\title{
MEDICAL ETHICS COURSE IMPROVES MEDICAL PROFESSIONALISM: MEDICAL STUDENTS` OPINIONS
}

\author{
${ }^{1}$ Abdolreza Sotoodeh Jahromi, ${ }^{2}$ Mehrnoosh Maalhagh, \\ ${ }^{2}$ Fateme Mohseniyan, ${ }^{1}$ Alireza Yousefi and ${ }^{3}$ Abdoulhossein Madani \\ ${ }^{1}$ Research Center for Social Determinants of Health, \\ Jahrom University of Medical Sciences, Jahrom, Iran \\ ${ }^{2}$ Student Research Committee, Jahrom University of Medical Sciences, Jahrom, Iran \\ ${ }^{3}$ Research Center for Social Determinants in Health Promotion, \\ Hormozgan University of Medical Science, Bandarabbas, Iran
}

Received 2014-05-23; Revised 2014-07-10; Accepted 2014-07-12

\begin{abstract}
Training physicians who are expert in many medical aspects is the most improtant mission of medical universities. One of these aspects, is professional behavior achievement. One of the important goals in training of ethics, is recognition of conflicts in different parts of ethics and having logical viewpoint for resolving and analyzing these conflicts. This descriptive and analytical study was done to evaluate the efficacy of medical ethics education in medical students' professional attitudes improvement. One hundred and two medical students were selected randomly in different steps of education and were questioned and their opinions correlation with stage of education and gender were evaluated. There was a significant difference between female viewpoint (in roles of ethic course which is presented in preclinical step in professional attitude improvement $)(P=0.009)$ and also a significant difference was seen in the viewpoint score between student stage with intern stage $(P=0.031)$. Medical students in educational student stage believe ethic course improve medical professionalism. Since there is no special course to train medical students in professionalism, some interventions are required in this field to improve this aspect of physicians' professional life.
\end{abstract}

Keywords: Medical Professionalism, Medical Ethics, Education Course, Medical Student

\section{INTRODUCTION}

The mission of medical universities is, to train physicians who are expert in many medical features. One of these characteristics, is achieving professional performance, which called medical professionalism. Recently, medical ethics has became a great concern as technology developments predispose different ways of abuses and misapplications (Larijani, 2011). Therefore training in ethics and professionalism is a fundamental component of medical education to prevent and resolve ethical problems (Goold, 2006).

One of the important goals in training of ethics is recognition of conflicts in different aspects of ethics and having logical viewpoint for resolving and analyzing these conflicts (Eckles, 2005).

In fact the aim of medical professionalism training is to premier patients' gains and influence attitudes including respect, responsibility, devotion, honesty and trusteeship (Yamani, 2010). Training professional behavior must create physicians who decide independently in all aspects (Laura, 2005). Also medical students may involve with some difficult conditions in future which requires skill set for analyzing and resolving ethical dilemma (Eckles, 2005).

Medical ethics which introduce the rules, norms and also discuss medical condition in aspect of ethics is presented to medical students before clinical courses (Ganasegeran, 2014).

Corresponding Author: Fateme Mohseniyan, Student Research Committee, Jahrom University of Medical Sciences, Jahrom, Iran 
Although medical students must attain their professional attitudes during their education based on their confrontation with patients and their masters experiences, it's not obvious that how medical ethics course improve professional behavior in medical students.

The aim of this descriptive and analytical study was to evaluate the efficacy of medical ethics education in medical students' professional attitudes improvement.

\section{MATERIALS AND METHODS}

This descriptive and analytical research was carried out on 102 medical students (78 female and 34 male) whom were selected randomly in different steps of education (student, extern and intern). Medical students were questioned about their viewpoints in roles of ethic course which is presented in preclinical step in professional attitude improvement and also about their gender. The questionnaire included 12 questions which scaled based on Likert scale.

Data analysis was done by SPSS version 15 software using T-test and ANOVA. P-Value less than 0.05 were considered as significant.

This Research work has been approved by ethics committee of Jahrom University of medical sciences.

\section{RESULTS}

A significant difference was found between female viewpoint (in roles of ethic course in preclinical step in professional attitude improvement) score $(49.436 \pm 9.066)$ and male viewpoint score $(44.206 \pm 9.521)(\mathrm{P}=0.009)$.

There was a statistically significant difference in the viewpoint score between educational student stage with educational intern phase (Mean Difference: 6.692, Standard error: 3.064, $\mathrm{P}=0.031)$.

But there were not seen significant differences in the viewpoint score among educational student stage with educational extern stage (Mean Difference: 3.535, Standard error: 1.837, $\mathrm{P}=0.057$ ) and also in the viewpoint score between educational extern stage with educational intern stage (Mean Difference: 3.157, Standard error: 3.096, $\mathrm{P}=0.310)$.

\section{DISCUSSION}

The result of present study indicated that female student had a greater score in viewpoint about the roles of ethic course in professional attitude improvement than male students' which indicating female students believe ethic course improves medical professionalism.

Also medical students in educational student stage had a greater score in the opinion than students in other educational stages which means medical students in educational student stage believe ethic course improve medical professionalism.

In the other word medical students in educational student stage, willing to learn this aspect of their profession to mature their professional identity as a physician that is critical steps in becoming a good physician, so they have more positive point of view about this course.

As different content and formats may be needed for preclinical and clinical students and future ethics programs may need to consider the varying ethical values and attitudes of medical students (Laura, 2005).

Although various researchers have suggested that the hidden curriculum within medical education has a prominent role in stunting the development of professionalism among future physicians, there has been minimal discussion of how the content of the hidden curriculum actually function to this end (Michalec, 2013). In other words there is an implicit lesson which is parallel to what medical students learn theoretically, which consists of values, norms and prospects (Yamani, 2010).

One of the standard methods of professional teaching is to train the students in clinical setting (Yamani, 2010). In this method medical students will be involved with real cases and it's a sort of active education. Also suitable time for professional training must be considered because preclinical students can't perceive the critical conditions and the efficacy of this kind of training is under question.

\section{CONCLUSION}

Since there is no special course to train medical students in professionalism, some interventions are required in this field to improve this aspect of physicians' professional life. Further research are recommended with larger sample in other medical university to evaluate the impact of medical ethics course on improvement of medical professionalism.

\section{ACKNOWLEDGEMENT}

This research work has been financed by Jahrom University of Medical Sciences. Authors are thankful to all medical students for their enrolments in this study. 


\section{REFERENCES}

Larijani, B., 2011. Modern methods of teaching medical ethics. Ethics Med. Res. Clin. Depart., 4: 39-46.

Goold, S.D., 2006. Ethics and professionalism: What does a resident need to learn. Am. J. Bioeth., 6: 917. PMID: 16885093

Eckles, R.E., 2005. Medical ethics education: Where are we? Where should we be going? Rev. Acad. Med., 80: 1143-1152. PMID: 16306292

Yamani, N., 2010. How do medical students learn professionalism during clinical education? A qualitative study of faculty members' and interns' experiences. Iran. J. Med. Educ., 9: 382-395.
Laura, W., 2005. Becoming a good doctor: Perceived need for ethics training focused on practical and professional development topics. Acad. Psychiatry, 29: 301-309. DOI: 10.1176/appi.ap.29.3.301

Ganasegeran, K., 2014. Medical professionalism from a socio-cultural perspective: Evaluating medical residents communicative attitudes during the medical encounter in Malaysia. J. Postgrad. Med., 60: 12-15. DOI: 10.4103/0022-3859.128799

Michalec, B., 2013. Stunting professionalism: The potency and durability of the hidden curriculum within medical education. Social Theory Health., 11: 388-406. DOI: $10.1057 /$ sth.2013.6 